\title{
Postoperative opioid sparing with injectable hydroxypropyl- $\beta$-cyclodextrin-diclofenac: pooled analysis of data from two Phase III clinical trials
}

This article was published in the following Dove Press journal: Journal of Pain Research

20 December 2016

Number of times this article has been viewed

\section{Tong J Gan'}

Neil Singla ${ }^{2}$

Stephen E Daniels ${ }^{3}$

Douglas A Hamilton ${ }^{4,5}$

Peter G Lacouture ${ }^{6,7}$

Christian RD Reyes ${ }^{8}$

Daniel B Carr ${ }^{4,9}$

'Department of Anesthesiology, Stony Brook University, NY, ${ }^{2}$ Lotus

Clinical Research, LLC, Pasadena, CA, ${ }^{3}$ Premier Research, Austin, TX, ${ }^{4}$ Javelin Pharmaceuticals, Inc., Cambridge, MA, ${ }^{5} \mathrm{New}$ Biology Ventures, LLC, San Mateo, CA, ${ }^{6}$ Magidom Discovery, LLC, St Augustine, FL, ${ }^{7}$ Department of Emergency Medicine, Brown University School of Medicine, Providence, RI, ${ }^{8}$ Hospira Inc., Lake Forest, IL, ${ }^{9}$ Department of Anesthesiology, Tufts Medical Center, Boston, MA, USA
Correspondence: Daniel B Carr Department of Anesthesiology, Tufts Medical Center, \#298, 800 Washington Street, Boston, MA 02III, USA

$\mathrm{Tel}+\mathrm{I} 6176369710$

Fax +I 6176369709

Email daniel.carr@tufts.edu
Purpose: Use of nonopioid analgesics (including nonsteroidal anti-inflammatory drugs) for postoperative pain management can reduce opioid consumption and potentially prevent opioid-related adverse events. This study examined the postoperative opioid-sparing effect of repeated-dose injectable diclofenac formulated with hydroxypropyl- $\beta$-cyclodextrin (HPßCD)-diclofenac.

Patients and methods: Pooled data from two double-blind, randomized, placebo- and active comparator-controlled Phase III trials were analyzed. Patients received HP $\beta C D$-diclofenac, placebo, or ketorolac by intravenous injection every 6 hours for up to 5 days following abdominal/ pelvic or orthopedic surgery. Rescue opioid use was evaluated from the time of first study drug administration to up to 120 hours following the first dose in the overall study population and in subgroups defined by baseline pain severity, age, and HPßCD-diclofenac dose.

Results: Overall, 608 patients received $\geq 1$ dose of study medication and were included in the analysis. While $93.2 \%$ of patients receiving placebo required opioids, the proportion of patients requiring opioids was significantly lower for patients receiving $\mathrm{HP} \beta \mathrm{CD}$-diclofenac $(18.75,37.5$, or $50 \mathrm{mg}$ ) or ketorolac $(P<0.005$ for all comparisons). Mean cumulative opioid dose and number of doses were significantly lower among patients receiving HP $\beta C D$-diclofenac versus placebo for the $0-24$ through $0-120$ hour time periods $(P<0.0001)$, as well as versus ketorolac for the $0-72$ through $0-120$ hour time periods $(P<0.05)$. HP $\beta C D$-diclofenac significantly reduced opioid consumption versus placebo in subgroups based on baseline pain severity (moderate, severe) and age ( $<65$ years, $\geq 65$ years) from the $0-24$ hour period onward. When compared to ketorolac, HP $\beta C D$-diclofenac also significantly reduced cumulative opioid consumption among patients with moderate baseline pain (0-72 through 0-120 hours) and opioid dose number among patients $\geq 65$ years old ( $0-24$ through $0-120$ hours).

Conclusion: $\mathrm{HP} \beta C D$-diclofenac can reduce postoperative opioid requirements. As this analysis was not powered to compare opioid-related adverse event rates, follow-up studies examining the clinical impact of HP $\beta C D$-diclofenac's opioid sparing are warranted.

Keywords: postoperative pain, nonsteroidal anti-inflammatory drugs, nonopioid analgesics, multimodal analgesia, diclofenac, cyclodextrin

\section{Introduction}

Opioids exert their analgesic effects by opioid receptors and are commonly used to manage postoperative pain either alone or in combination with other analgesics. ${ }^{1-3}$ In the postoperative setting, opioid use can be accompanied by adverse events (AEs) such as postoperative nausea and vomiting, bladder dysfunction, drowsiness, sedation, and constipation, which can delay recovery and discharge..$^{4-8}$ Opioid use can also lead 
to acute tolerance, increased costs of care, and increased morbidity. ${ }^{5,9-12}$ In addition to concerns in the general surgical patient population, specific patient groups, such as the elderly, may be particularly sensitive to the effects of opioids and more susceptible to risks of opioid-related AEs. ${ }^{13}$

Alternatively, nonsteroidal anti-inflammatory drugs (NSAIDs) exert analgesic and anti-inflammatory effects by cyclooxygenase inhibition ${ }^{3}$ and represent a key aspect of multimodal postoperative analgesia, the goal of which is to provide appropriate analgesia while minimizing the AEs associated with given drug classes. ${ }^{6,9,14-18}$ A growing body of data supports the ability of multimodal analgesia regimens to reduce postoperative opioid consumption and, therefore, the incidence of opioid-related AEs that can slow postoperative recovery. ${ }^{2,4,6,9,12,19-31}$

Diclofenac is a nonselective NSAID with an established efficacy and tolerability profile that is available in multiple formulations and is used to treat acute and chronic pain. ${ }^{32,33}$ Hydroxypropyl- $\beta$-cyclodextrin (HP $\beta C D$ )-diclofenac (Dylo$\left.\mathrm{ject}^{\mathrm{TM}}\right)$ is an injectable formulation of diclofenac sodium that is solubilized with $\mathrm{HP} \beta \mathrm{CD}$, does not require dilution, and is administered intravenously (IV) as a low-volume bolus injection. ${ }^{34}$ In contrast, a previous formulation of diclofenac for IV administration (Voltarol ${ }^{\mathrm{TM}}$ [Novartis Pharmaceuticals UK Ltd, Surrey UK]; formulated with propylene glycol and benzyl alcohol) requires dilution and infusion over a period of 30-120 minutes. ${ }^{35,36}$ Previous studies have demonstrated the safety and efficacy of single- and multipledose HP $\beta C D$-diclofenac in postsurgical patients, ${ }^{37-40}$ and HP $\beta C D$-diclofenac is indicated for the management of mild to moderate pain and moderate to severe pain, alone or in combination with opioid analgesics. ${ }^{41}$

Given the benefits of reducing postoperative opioid use, the objective of the current evaluation was to examine the opioid-sparing effect (ie, efficacy assessed based on rescue opioid use $^{42}$ ) of multiple-dose HP $\beta C D$-diclofenac by pooled analysis of data from two Phase III clinical trials. It was hypothesized that this analysis would reveal significant opioid-sparing effects of HP $\beta C D$-diclofenac with respect to overall consumption as well as frequency of use (ie, number of doses). While some data on postsurgical opioid usage in patients receiving $\mathrm{HP} \beta C D$-diclofenac has been reported for the individual studies included here, ${ }^{39,40}$ the present analysis provides an in-depth examination of this key clinical endpoint from multiple perspectives and in a broader patient population.

\section{Patients and methods}

Individual studies included in this analysis were registered with clinicaltrials.gov (NCT00448110, NCT00507026), and following Institutional Review Board (IRB) approval, all patients provided IRB-approved written informed consent. Detailed methods for the individual studies have been previously reported..$^{39,40}$

\section{Patients}

Patients were screened for study inclusion if they were scheduled for an abdominal/pelvic or orthopedic procedure within 2 weeks (abdominal/pelvic) or 3 weeks (orthopedic) and were expected to require IV analgesia for postoperative pain. Key inclusion criteria for both studies were: age $\geq 18$ years and moderate to severe pain $\leq 6$ hours following surgery (pain intensity $\geq 50 \mathrm{~mm}$ on a $0-100 \mathrm{~mm}$ visual analog scale [VAS]). The upper age limit was 65 years in the abdominal/pelvic surgery study and 85 years in the orthopedic surgery study. Females of childbearing age were required to have a negative pregnancy test at screening, as well as to be practicing abstinence or an approved method of contraception. Key exclusion criteria were: a history of uncontrolled chronic disease; recent history ( $\leq 6$ months) of cardiovascular events (eg, myocardial infarction, stroke); known allergy to diclofenac, NSAIDs, morphine, anesthetics, or excipients of the study preparation; clinically significant lab or electrocardiograph (ECG) results at baseline or screening; use of monoamine oxidase inhibitors, tryptophan, carbamazepine, or valproate $\leq 2$ weeks prior to taking study drug; use of aspirin (except for antiplatelet cardiac protection), other NSAIDs, or other common centrally or peripherally acting analgesic drugs, centrally acting adjuvants, major and minor tranquilizers, or antihistamines $\leq 24$ hours prior to study drug administration (with the exception of medications administered during the procedure); and use of a long-acting NSAID or cyclooxygenase- 2 inhibitor $\leq 3$ days prior to surgery. Patientcontrolled analgesia was not permitted postoperatively, either prior to or during drug dosing.

\section{Study design and outcomes}

The included studies were identified based on their similar design, patient populations, duration of treatment, and endpoints. Both studies were Phase III trials with a randomized, double-blind, multicenter, multiple-dose, placebo- and active comparator-controlled design. In both studies, patients were randomized to receive HP $\beta C D$-diclofenac $\left(\right.$ Dyloject $^{\mathrm{TM}}$; Hospira, Inc., a Pfizer company, Lake Forest, IL, USA), ketorolac, or placebo, according to a computer-generated random number code. Investigators, clinical staff, and patients were blinded to treatment group assignment. Dose levels of individual study treatments in the orthopedic surgery 
study were not blinded, however. Patients in the abdominal/ pelvic surgery study received 18.75 or $37.5 \mathrm{mg}$ HP $\beta C D$ diclofenac (based on randomization), $30 \mathrm{mg}$ ketorolac, or placebo. Patients in the orthopedic surgery study received either 18.75, 37.5, or $50 \mathrm{mg}$ HP $\beta C D$-diclofenac, based on the presence of defined risk factors. The standard dose was $37.5 \mathrm{mg}$; however, patients weighing $<50 \mathrm{~kg}$, aged $\geq 65$ years, or with NSAID-related gastrointestinal risk factors, hepatic impairment, or renal insufficiency (based on serum creatinine and blood urea nitrogen measures being greater than the upper limit of normal) received the $18.75 \mathrm{mg}$ dose, and patients $\geq 95 \mathrm{~kg}$ with no predefined risk factors received 50 mg. Dose adjustment of ketorolac in the orthopedic surgery study was similar. Patients $<65$ years old and without renal insufficiency received a standard dose of $30 \mathrm{mg}$, while highrisk patients received $15 \mathrm{mg}$.

Study medication was given as an IV bolus injection, with the first dose given $\leq 6$ hours following surgery to patients reporting moderate to severe pain on the VAS. The time of first study drug administration was taken as time 0 , and subsequent doses were given every 6 hours until discharge or withdrawal/discontinuation. In the abdominal/pelvic surgery population, patients were observed for at least 48 hours following the first study drug dose, and for up to 5 days; in the orthopedic surgery population, patients were observed for at least 24 hours, and for up to 5 days. Safety was monitored throughout both studies by physical examinations, laboratory testing, vital signs, ECG, AEs, and evaluation of thrombophlebitis and wound healing (safety data previously reported $\left.{ }^{39,40,43}\right)$.

\section{Assessments of opioid use}

In both studies, rescue medication (IV morphine, bolus, maximum $7.5 \mathrm{mg}$ every 3 hours) was made available upon patient request any time after the initial dose of study drug was given. However, patients were encouraged to wait for at least 30 minutes after study drug administration in the orthopedic surgery study and at least 1 hour after study drug administration in the abdominal/pelvic surgery study to request for opioids. Patients in the abdominal/pelvic surgery study received a $5 \mathrm{mg}$ IV bolus of morphine upon request, followed by titration to $7.5 \mathrm{mg}$, every 3 hours if needed. Patients in the orthopedic surgery study received IV bolus morphine in $2.5 \mathrm{mg}$ increments, up to $7.5 \mathrm{mg}$, every 3 hours. Though encouraged to wait, patients were not denied rescue opioids in the event of requests made prior to 30 minutes (orthopedic surgery) or 1 hour (abdominal/pelvic surgery) after the first study drug dose was given. If the rescue opioids did not provide adequate analgesia, the patient was withdrawn from the study and given pain medication in accordance with the investigator's usual practice. Opioid use was recorded throughout the treatment period (from the time of first study drug administration to up to 120 hours [5 days] following first administration). The outcomes examined in this pooled analysis were: 1) proportion of patients requiring opioids; 2) cumulative opioid dose for the $0-24,0-48$, 0-72, 0-96, and 0-120 hour intervals following first study drug administration; and 3) cumulative number of opioid doses received for the $0-24,0-48,0-72,0-96$, and $0-120$ hour intervals following first study drug administration. Comparisons were made between patients receiving either active treatment (HP $\beta C D$-diclofenac, ketorolac) and placebo, as well as between patients receiving either active treatment.

\section{Statistical analysis}

Sample size in each study was established by defining values for the number of patients required to detect a clinically significant difference in the study's primary efficacy measure. Analyses of rescue opioid use were performed on the combined intent-to-treat population from both studies using Statistical Analysis System (SAS Institute Inc., Cary, NC, USA) version 9.1 or later. Pooled data are presented as mean \pm standard deviation (SD), unless otherwise noted. Data were analyzed for the pooled study population, as well as subgroups based on dose (HP $\beta C D$-diclofenac 18.75, 37.5 , and $50 \mathrm{mg}$ ), baseline pain (moderate or severe, based on $0-100 \mathrm{~mm}$ VAS), and age ( $<65$ and $\geq 65$ years). $P$-values for demographic data were calculated using analysis of variance for numerical variables and Cochran-Mantel-Haenszel test for categorical variables. $P$-values for efficacy outcomes (rescue opioid use; HP $\beta C D$-diclofenac and ketorolac vs placebo; HP $\beta C D$-diclofenac vs ketorolac) were calculated using least-square mean difference based on an analysis of covariance model with treatment, study, and center as factors and baseline pain as a covariate.

\section{Results Study population}

Patient disposition for the pooled population has been previously reported in Gan et al. ${ }^{44}$ In total, 608 surgical patients were included in the analysis (HP $\beta C D$-diclofenac: $n=318$; ketorolac: $n=142$; placebo: $n=148$ ). Within the $\mathrm{HP} \beta C D$-diclofenac group, $\mathrm{n}=132$ patients received $\mathrm{HP} \beta C D$ diclofenac $18.75 \mathrm{mg}, \mathrm{n}=150$ received $\mathrm{HP} \beta C D$-diclofenac $37.5 \mathrm{mg}$, and $\mathrm{n}=36$ received $\mathrm{HP} \beta C D$-diclofenac $50 \mathrm{mg}$. Within the ketorolac group, $\mathrm{n}=18$ patients received ketorolac 
$15 \mathrm{mg}$ and $\mathrm{n}=124$ patients received ketorolac $30 \mathrm{mg}$. Patients receiving $\mathrm{HP} \beta C D$-diclofenac, ketorolac, or placebo did not differ significantly with respect to age, sex, or procedure type or duration (Table 1). As per the individual study inclusion criteria, all patients had moderate or severe baseline pain. The proportion of patients with severe baseline pain was similar across treatment groups (HP $\beta C D$-diclofenac: $41.8 \%$ [n=133/318]; ketorolac: $40.8 \%$ [n=58/142]; placebo: $38.5 \%$ $[\mathrm{n}=57 / 148])$.

\section{Rescue opioid consumption: all patients}

In total, $93.2 \%$ of patients in the placebo group required rescue opioids (Figure 1). The proportion of patients receiving opioids was significantly lesser than that receiving placebo for all HP $\beta C D$-diclofenac dose groups (18.75 mg: 79.5\% [P=0.0017]; $37.5 \mathrm{mg}: 68.0 \%[P<0.0001] ; 50 \mathrm{mg}: 72.2 \%$ $[P<0.0001]$; all dose groups: $73.3 \%[P<0.0001])$ (Figure 1$)$. Similarly, significantly lesser number of patients in the ketorolac group required opioids as compared to placebo (68.3\%,P<0.0001).

Overall, the majority of opioid consumption across all treatment groups occurred in the first 24 hours following the first study drug administration (Figure 2; Table S1). Over the $0-120$ hour period, patients in the HP $\beta C D$-diclofenac 18.75, 37.5 , and $50 \mathrm{mg}$ groups received an average of $9.31 \pm 10.35$, $7.41 \pm 9.48$, and $8.94 \pm 10.00 \mathrm{mg}$ of rescue opioids, respectively (8.37 $\pm 9.92 \mathrm{mg}$ for all HP $\beta C D$-diclofenac patients combined), while patients in the ketorolac group received, on average, $10.61 \pm 14.68 \mathrm{mg}$ and patients in the placebo group received
17.69 $\pm 14.94 \mathrm{mg}$ of rescue opioids. All HP $\beta C D$-diclofenac doses, as well as ketorolac were associated with significantly lower mean cumulative opioid consumption versus placebo for the $0-24$ through $0-120$ hour time periods $(P<0.0001)$. Patients receiving HP $\beta C D$-diclofenac required, on average, significantly lower cumulative opioid doses than those receiving ketorolac for the $0-72$ through $0-120$ hour periods ( $8.34 \pm 9.85$ vs $10.57 \pm 14.64 \mathrm{mg}, P=0.034$ for $0-72$ hours) (Figure 2; Table S1), but there was no significant difference between the HP $\beta C D$-diclofenac and ketorolac groups for the $0-24$ hour period $(P=0.30)$ or the $0-48$ hour period $(P=0.068)$. In addition, patients receiving HP $\beta C D$-diclofenac $37.5 \mathrm{mg}$ required significantly lower cumulative amounts of opioid than the patients receiving ketorolac (30 or 15 $\mathrm{mg})$, beginning with the $0-48$ hour period $(7.25 \pm 9.22$ vs $9.74 \pm 11.80 \mathrm{mg} ; P=0.020$ ) and through the $0-120$ hour period (7.41 \pm 9.48 vs $10.61 \pm 14.68 \mathrm{mg} ; P=0.009)$.

Similar to total cumulative dose, the majority of opioid doses were received during the $0-24$ hour period and patients in all HP $\beta C D$-diclofenac dose groups as well as in the ketorolac group required significantly fewer opioid doses than patients in the placebo group for all time periods $(P<0.0001)$ (Figure 3; Table S1). Patients receiving HP $\beta C D$-diclofenac required significantly fewer opioid doses than those receiving ketorolac for the $0-72$ through $0-120$ hour periods $(2.83 \pm 3.26$ doses vs $3.43 \pm 3.98$ doses; $P=0.038$ for $0-120$ hours), but not for the $0-24$ hour period $(P=0.20)$ or the $0-48$ hour period $(P=0.052)$. Furthermore, patients receiving HP $\beta C D$ diclofenac $37.5 \mathrm{mg}$ required significantly fewer opioid doses

Table I Summary of baseline demographics and surgical characteristics

\begin{tabular}{|c|c|c|c|c|}
\hline & HPßCD-diclofenac $(n=3 \mid 8)^{a}$ & Ketorolac $(n=142)$ & Placebo $(n=148)$ & $P$-value ${ }^{b}$ \\
\hline Mean age, years (SD) & $48.9(14.1)$ & $48.0(14.7)$ & $48.6(14.1)$ & 0.81 \\
\hline$<65, \mathrm{n}(\%)$ & $276(86.8)$ & $124(87.3)$ & $124(83.8)$ & 0.65 \\
\hline$\geq 65, \mathrm{n}(\%)$ & $42(13.2)$ & $18(12.7)$ & $24(16.2)$ & - \\
\hline \multicolumn{5}{|l|}{ Sex } \\
\hline Female, n (\%) & $233(73.3)$ & $107(75.4)$ & $107(72.3)$ & 0.83 \\
\hline Male, $\mathrm{n}(\%)$ & 85 (26.7) & $35(24.6)$ & $4 I(27.7)$ & - \\
\hline \multicolumn{5}{|l|}{ Procedure type $^{c}$} \\
\hline Abdominal/pelvic, n (\%) & $173(54.4)$ & $82(57.7)$ & $76(5 \mathrm{I} .4)$ & 0.55 \\
\hline Orthopedic, n (\%) & $145(45.6)$ & $60(42.3)$ & $72(48.6)$ & - \\
\hline Mean procedure duration, hours (SD) & $1.17(0.69)^{d}$ & $\mathrm{I} .13(0.65)^{\mathrm{e}}$ & $1.19(0.71)$ & 0.76 \\
\hline \multicolumn{5}{|l|}{ VAS pain score at baseline } \\
\hline Moderate, ${ }^{f}$ (\%) & $183(57.5)$ & $82(57.7)$ & $91(6 \mid .5)$ & 0.76 \\
\hline Severe, ${ }^{8}$ n (\%) & $133(4 \mid .8)$ & $58(40.8)$ & $57(38.5)$ & - \\
\hline Missing, n (\%) & $2(0.6)$ & $2(1.4)$ & 0 & - \\
\hline
\end{tabular}

Notes: ancludes $n=132$ patients receiving HP $\beta C D$-diclofenac $18.75 \mathrm{mg}, \mathrm{n}=150$ patients receiving HP $\beta C D$-diclofenac $37.5 \mathrm{mg}$, and $\mathrm{n}=36 \mathrm{fatients}$ receiving HP $\beta C D$-diclofenac

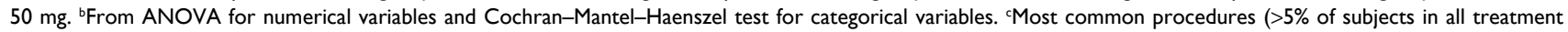
groups): abdominal hysterectomy, abdominal surgery, bunionectomy/foot bone, inguinal hernia repair, knee replacement, vaginal hysterectomy. ${ }^{d} n=3 \mid 6$, ${ }^{e}=|4|$. ${ }^{f} B a s e l i n e$ reported pain $\geq 50$ and $<70 \mathrm{~mm}$ on $0-100 \mathrm{~mm}$ VAS. BBaseline reported pain $\geq 70 \mathrm{~mm}$ on $0-100 \mathrm{~mm}$ VAS.

Abbreviations: ANOVA, analysis of variance; HP $\beta C D$, hydroxypropyl- $\beta$-cyclodextrin; SD, standard deviation; VAS, visual analog scale. 


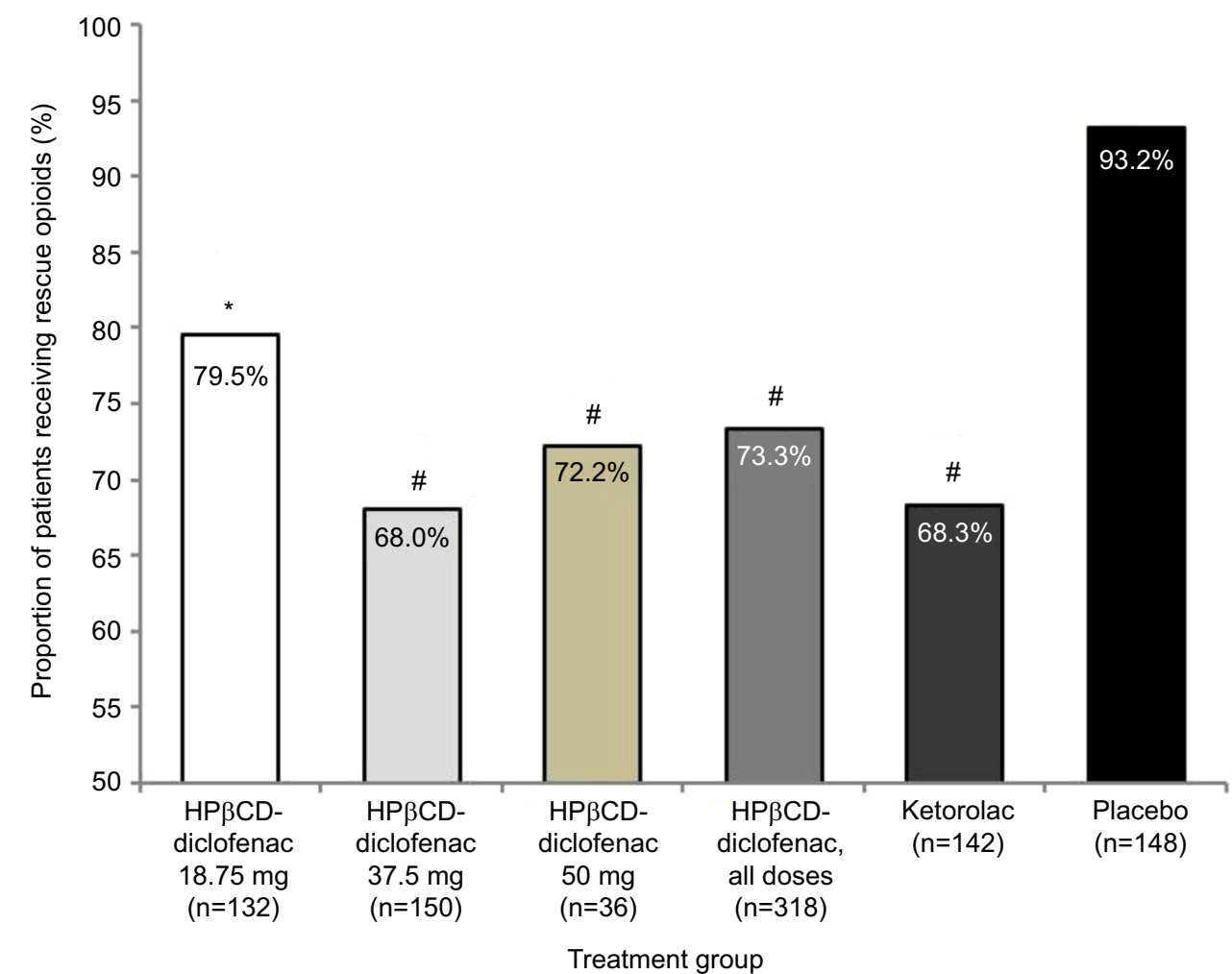

Figure I Rescue opioid use among patients receiving intravenous HPßCD-diclofenac, ketorolac, or placebo for acute postsurgical pain.

Notes: Data from the combined ITT populations are presented. ${ }^{*} P<0.005$ versus placebo, ${ }^{\#} P<0.000$ I versus placebo from least-square mean difference based on ANCOVA model with treatment, study, and center as factors and baseline pain as a covariate. There was no significant difference between any HP $\beta C D$-diclofenac dose and ketorolac. Abbreviations: ANCOVA, analysis of covariance; HP $\beta C D$, hydroxypropyl- $\beta$-cyclodextrin; ITT, intent to treat.

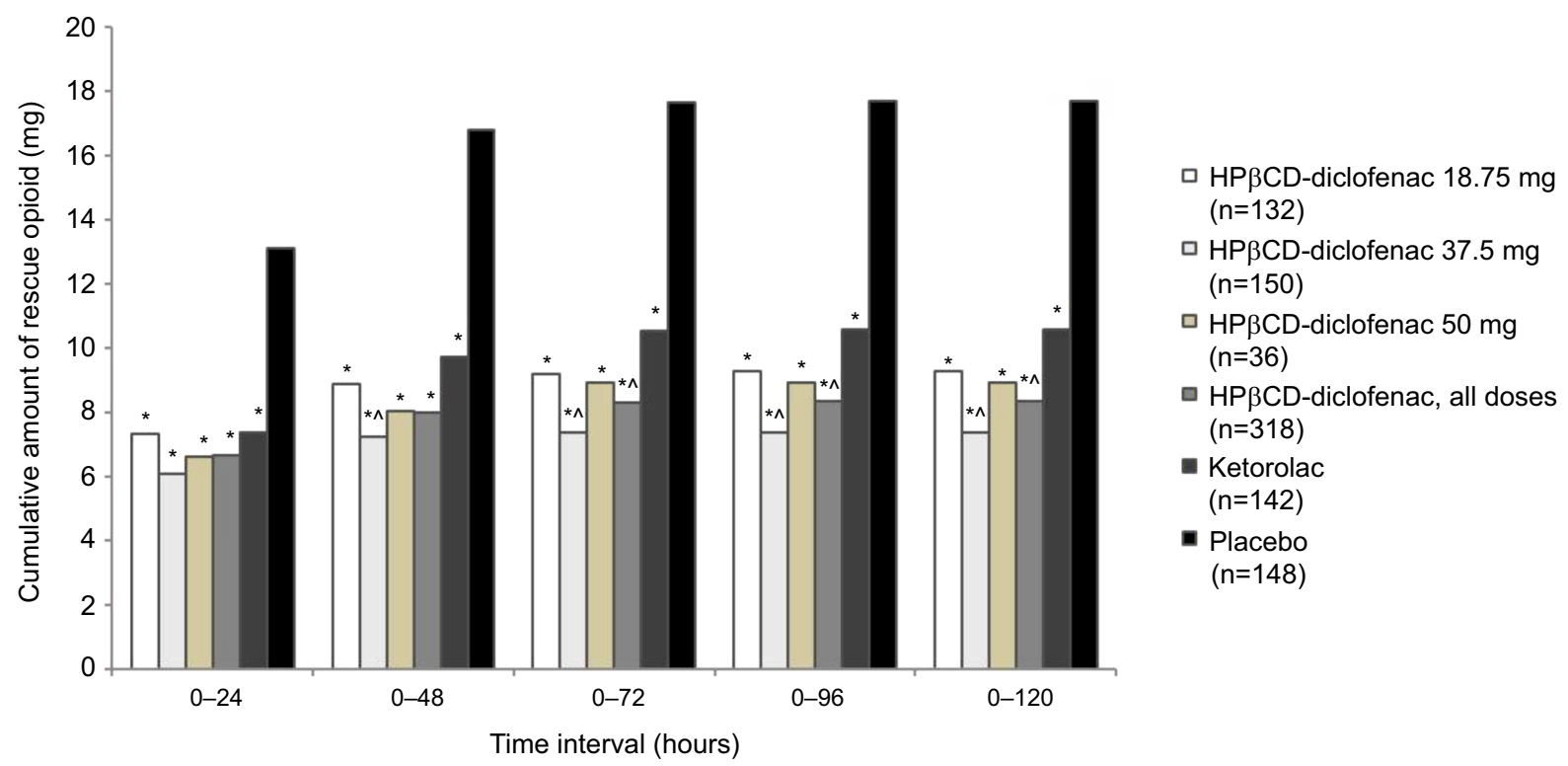

Figure 2 Total rescue opioid consumption among patients receiving intravenous HP $\beta C D$-diclofenac, ketorolac, or placebo for acute postsurgical pain.

Notes: Data from the combined ITT populations are presented. ${ }^{*} P<0.000$ I versus placebo, ${ }^{\wedge} P<0.05$ versus ketorolac from least-square mean difference based on ANCOVA model with treatment, study, and center as factors and baseline pain as a covariate. For mean values and SDs, see Table SI.

Abbreviations: ANCOVA, analysis of covariance; HP $\beta C D$, hydroxypropyl- $\beta$-cyclodextrin; ITT, intent to treat; SD, standard deviation.

than the patients receiving ketorolac, beginning at the $0-48$ hour interval $(2.29 \pm 2.98$ doses vs $3.22 \pm 3.55$ doses; $P=0.021)$ and through the $0-120$ hour interval $(2.34 \pm 3.04$ doses vs $3.43 \pm 3.98$ doses; $P=0.013$ ) (Figure 3; Table S1). HP $\beta C D$ - diclofenac was associated with a significantly longer median time to first rescue opioid dose than placebo (194.0 minutes [95\% confidence interval $\{\mathrm{CI}\}: 143.0-240.0$ minutes] vs 74.5 minutes [95\% CI: $57.0-96.0$ minutes]; $P<0.0001)$. 


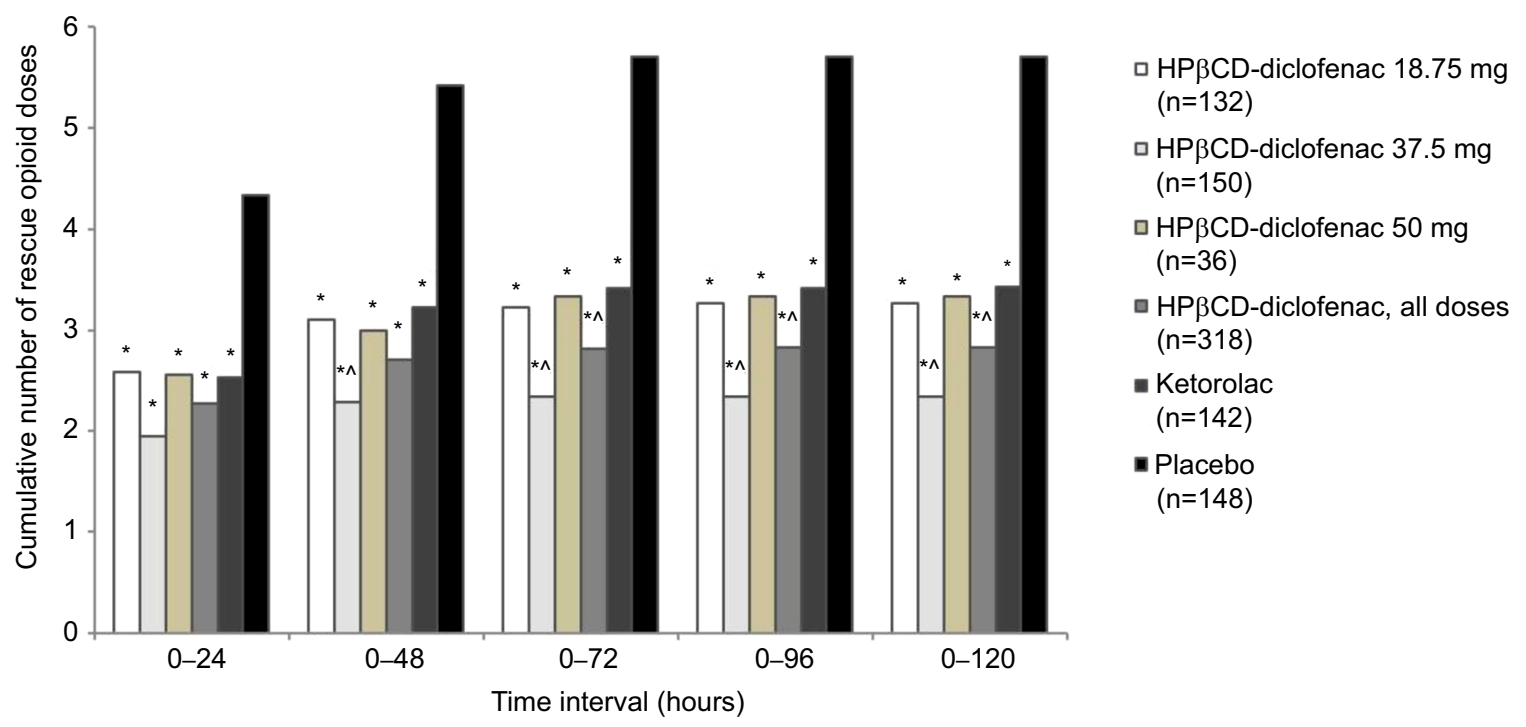

Figure 3 Total number of rescue opioid doses among patients receiving intravenous HP $\beta C D$-diclofenac, ketorolac, or placebo for acute postsurgical pain. Notes: Data from the combined ITT populations are presented. ${ }^{*} P<0.000$ I versus placebo, ${ }^{\wedge} P<0.05$ versus ketorolac from least-square mean difference based on ANCOVA model with treatment, study, and center as factors and baseline pain as a covariate. For mean values and SDs, see Table SI.

Abbreviations: ANCOVA, analysis of covariance; HP $\beta C D$, hydroxypropyl- $\beta$-cyclodextrin; ITT, intent to treat; SD, standard deviation.

Similarly, ketorolac significantly reduced median time to first rescue opioid dose versus placebo (203.0 minutes [95\% CI: 145.0-397.0 minutes]; $P<0.0001$ ), but there was no significant difference between HP $\beta C D$-diclofenac and ketorolac $(P=0.38)$.

\section{Rescue opioid consumption: by baseline pain and age subgroups}

For patients with moderate baseline pain $(\geq 50$ and $<70$ $\mathrm{mm}$ on the VAS), all HP $\beta C D$-diclofenac groups and the ketorolac group were associated with significantly reduced mean cumulative opioid consumption versus placebo for all time periods (all $P<0.005$ vs placebo) (Figure 4A; Table S2). Patients who received HP $\beta C D$-diclofenac had reduced opioid consumption versus patients who received ketorolac for the 0-72 hour period $(7.36 \pm 9.22 \mathrm{mg}$ vs $9.72 \pm 15.73 \mathrm{mg}$; $P=0.034)$ to $0-120$ hour period $(7.42 \pm 9.35 \mathrm{mg}$ vs $9.78 \pm 15.80$ mg; $P=0.035)$, but not for $0-24$ hours $(P=0.39)$ or $0-48$ hours $(P=0.071)$. Patients receiving HP $\beta C D$-diclofenac $37.5 \mathrm{mg}$ had significantly reduced mean cumulative opioid consumption versus patients receiving ketorolac, beginning at the $0-48$ hour period $(5.67 \pm 8.00 \mathrm{mg}$ vs $8.70 \pm 11.85 \mathrm{mg}$; $P=0.043$ ) and persisting through the $0-120$ hour period (5.77 $\pm 8.15 \mathrm{mg}$ vs $9.78 \pm 15.80 \mathrm{mg} ; P=0.018$ ). For patients with severe baseline pain ( $\geq 70 \mathrm{~mm}$ on the VAS), all active treatment groups were associated with significantly lower mean cumulative opioid consumption versus placebo (all $P<0.005)$. However, there was no significant opioid-sparing effect of HP $\beta C D$-diclofenac versus ketorolac (Figure 4B;
Table S2). In both subgroups based on baseline pain, all active treatment groups received significantly fewer opioid doses versus placebo ( $P<0.005$ for all time periods); however, no opioid-sparing effect of HP $\beta C D$-diclofenac versus ketorolac with respect to dose number was observed (Figure 5; Table S3).

Among patients $<65$ years old, all HP $\beta C D$-diclofenac dose groups as well as the ketorolac group required significantly fewer opioid doses than the placebo group $(P \leq 0.0001$ for all time periods) (Figure 6A; Table S4). No opioid-sparing effect was observed for HP $\beta C D$-diclofenac versus ketorolac. Patients $\geq 65$ years old received lower, risk-adjusted HP $\beta C D$ diclofenac and ketorolac doses. Patients in the HP $\beta C D-$ diclofenac $18.75 \mathrm{mg}$ group required significantly fewer opioid doses than those receiving placebo and ketorolac for all time periods $(P<0.05$ vs placebo, $P<0.05$ vs ketorolac) (Figure 6B; Table S4).

\section{Discussion}

The goal of postoperative analgesia is to optimally manage pain while minimizing the potential for adverse effects that can delay recovery or present risks to the patient. While opioids are efficacious analgesics, AEs associated with this drug class can be wide ranging and represent an important concern for clinicians and patients. ${ }^{2,49,45}$ Furthermore, opioid-related AEs in postsurgical patients are associated with increased hospital length of stay and added costs which recent studies have estimated to range from $\$ 4,707$ to $\$ 13,737$ per patient. ${ }^{9-11,46,47}$ Thus, multimodal pain management 

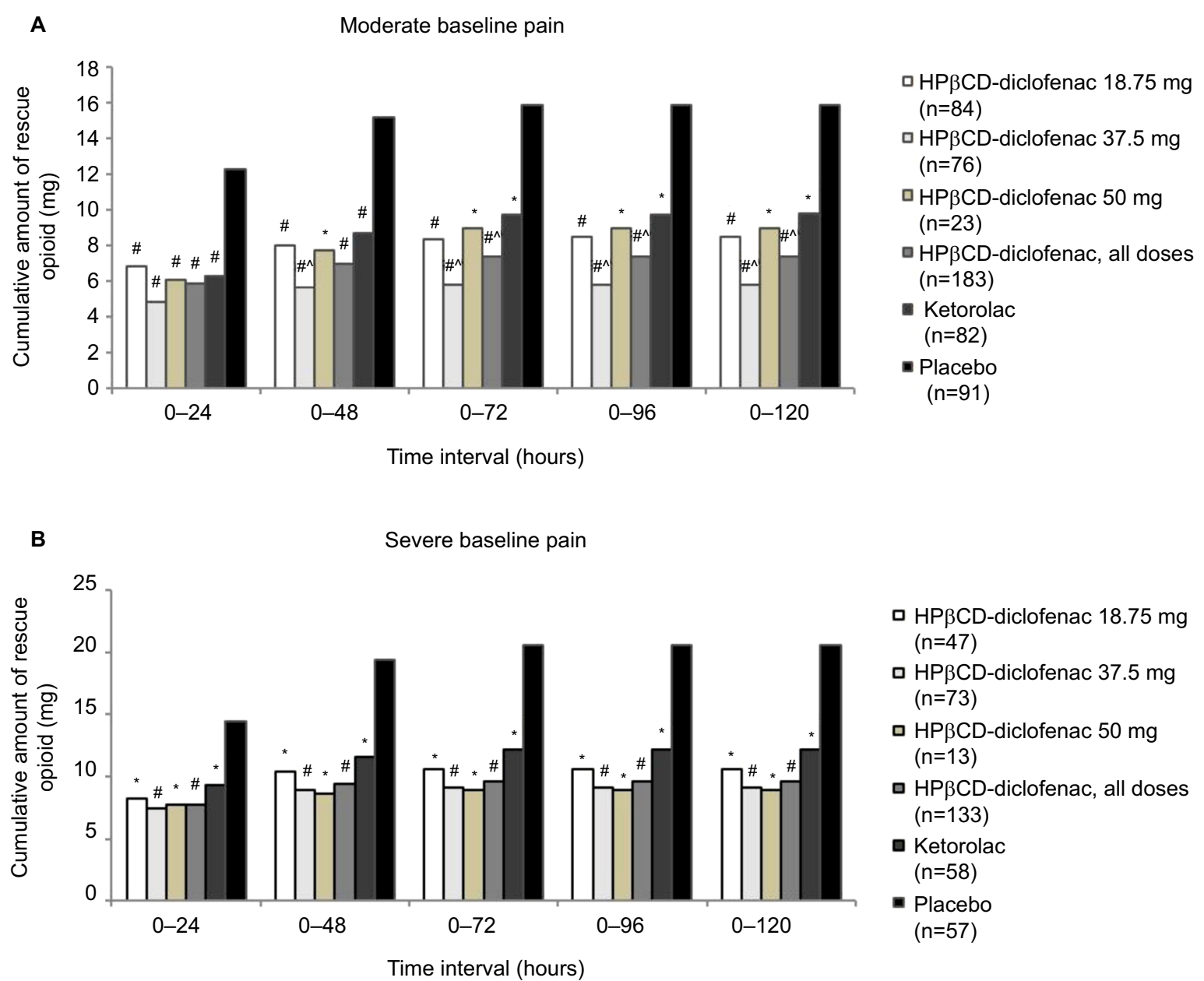

Figure 4 Total rescue opioid consumption, by baseline pain severity, among patients receiving intravenous HP $\beta C D$-diclofenac, ketorolac, or placebo for acute postsurgical pain.

Notes: Data are presented for patients with (A) moderate baseline pain $(\geq 50$ and $<70 \mathrm{~mm})$ and (B) severe baseline pain $(\geq 70 \mathrm{~mm})$ within 6 hours following surgery, as assessed on the $0-100 \mathrm{~mm}$ VAS. Data from the combined ITT populations are presented. ${ }^{P} P<0.005$ versus placebo, ${ }^{\#} P<0.000$ I versus placebo, ${ }^{\wedge} P<0.05$ versus ketorolac from least-square mean difference based on ANCOVA model with treatment, study, and center as factors and baseline pain as a covariate. For mean values and SDs, see Table S2.

Abbreviations: ANCOVA, analysis of covariance; HP $\beta C D$, hydroxypropyl- $\beta$-cyclodextrin; ITT, intent to treat; SD, standard deviation; VAS, visual analog scale.

approaches that make use of analgesics with different mechanisms of action, such as the NSAIDs, are recommended. ${ }^{31,48}$

The results of this analysis of data from two Phase III trials reveal that repeated-dose HP $\beta C D$-diclofenac was associated with a significant opioid-sparing effect when given for up to 5 days for moderate to severe pain following abdominal/ pelvic or orthopedic surgery. In addition, HP $\beta C D$-diclofenac (37.5 mg dose groups and all dose groups combined) demonstrated significant opioid-sparing effects in comparison to the active comparator ketorolac, a drug currently used in clinical practice, with respect to both cumulative rescue opioid dose and the number of doses. There were no discernible differences in baseline pain level (moderate, severe) between comparator groups, suggesting that the observed differences are not likely due to differences in baseline pain. Notably, opioid consumption appeared to be lowest in the HP $\beta C D$ - diclofenac $37.5 \mathrm{mg}$ group. While potential reasons for this were not investigated, it is noteworthy that $37.5 \mathrm{mg}$ is the standard HP $\beta C D$-diclofenac dose and was given to patients without defined risk factors, while the $50 \mathrm{mg}$ dose was given to patients weighing $\geq 95 \mathrm{~kg}$. The results of this analysis expand upon previously reported data from the individual studies, which showed that HP $\beta C D$-diclofenac was associated with increased time to rescue opioid administration and reduced opioid consumption over 72 hours versus placebo in abdominal/pelvic surgery patients, ${ }^{39}$ as well as increased time to rescue opioid administration and reduced opioid consumption over 120 hours versus placebo in orthopedic surgery patients. ${ }^{40}$

Pooled analysis allowed for in-depth examination of opioid consumption in terms of cumulative dose and number of doses, both in the entire population as well as in 
A

Moderate baseline pain

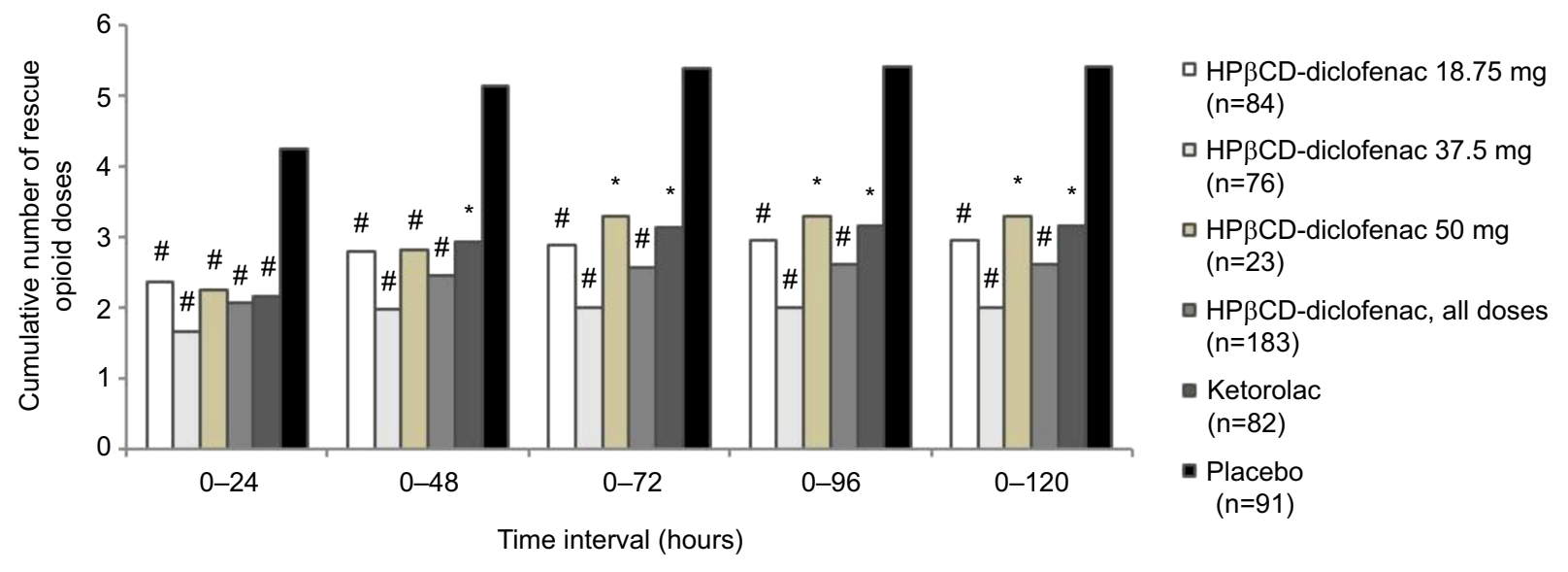

B

Severe baseline pain

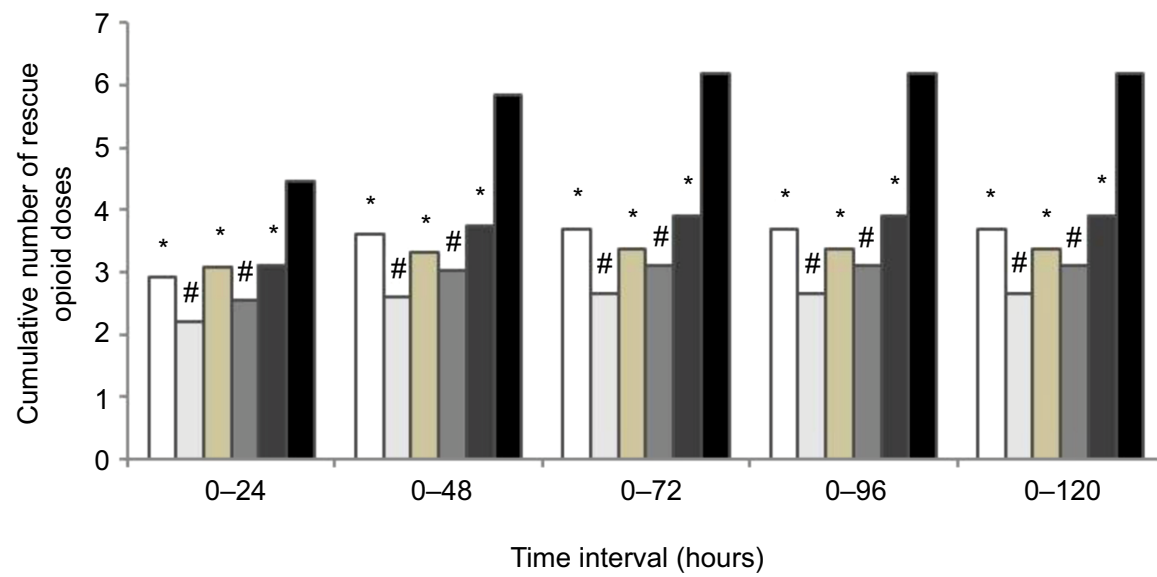

$\square$ HP $\beta C D$-diclofenac $18.75 \mathrm{mg}$ $(n=47)$

HP $\beta C D$-diclofenac $37.5 \mathrm{mg}$ $(n=73)$

HPßCD-diclofenac $50 \mathrm{mg}$ $(n=13)$

- HP $\beta C D$-diclofenac, all doses $(n=133)$

- Ketorolac $(n=58)$

- Placebo $(n=57)$

Figure 5 Total number of rescue opioid doses, by baseline pain severity, among patients receiving intravenous HP $\beta C D$-diclofenac, ketorolac, or placebo for acute postsurgical pain.

Notes: Data are presented for patients with (A) moderate baseline pain ( $\geq 50$ and $<70 \mathrm{~mm}$ ) and (B) severe baseline pain ( $\geq 70 \mathrm{~mm})$ within 6 hours following surgery, as assessed on the $0-100 \mathrm{~mm}$ VAS. Data from the combined ITT populations are presented. $* P<0.005$ versus placebo, ${ }^{\#} P \leq 0.000 \mathrm{I}$ versus placebo versus ketorolac from leastsquare mean difference based on ANCOVA model with treatment, study, and center as factors and baseline pain as a covariate. For mean values and SDs, see Table S3.

Abbreviations: ANCOVA, analysis of covariance; HP $\beta C D$, hydroxypropyl- $\beta$-cyclodextrin; ITT, intent to treat; SD, standard deviation; VAS, visual analog scale.

the key patient subgroups defined by HP $\beta C D$-diclofenac dose received, baseline postsurgical pain, and age. This stratification revealed that HP $\beta C D$-diclofenac provided postoperative opioid-sparing advantages over ketorolac in patients with moderate pain (lower cumulative opioid consumption, $0-72$ through $0-120$ hour periods), as well as in patients $\geq 65$ years old (fewer opioid doses, 0-24 through 0-120 hour periods). This analysis did not compare opioid consumption in patients with moderate versus severe pain specifically; however, the results do indicate significant reduction in total consumption and the number of doses for both active treatments in comparison to placebo, independent of the baseline pain level. This is consistent with previously reported efficacy measures from the two Phase III trials. ${ }^{39,40}$ In addition, this study examined only patients undergoing a single surgical procedure during their admission. The opioid-sparing effects of HP $\beta C D$-diclofenac in patients undergoing multiple procedures, which might necessitate increasingly complex pain management regimens, remain to be elucidated.

It is important to note that the analgesic properties of NSAIDs are not solely attributable to their anti-inflammatory effects, and there is growing evidence that diclofenac has a range of mechanisms of action that differ from other drugs in the NSAID class. ${ }^{33}$ In addition to the well-known anti-inflammatory mechanism of action of NSAIDs, putative mechanisms of action of diclofenac include inhibition of leukotriene synthesis, inhibition of phospholipase A2, and modulation of arachidonic acid levels, as well as stimulation of peripheral nitric oxide-cyclic guanosine 
A

Age $<65$ years

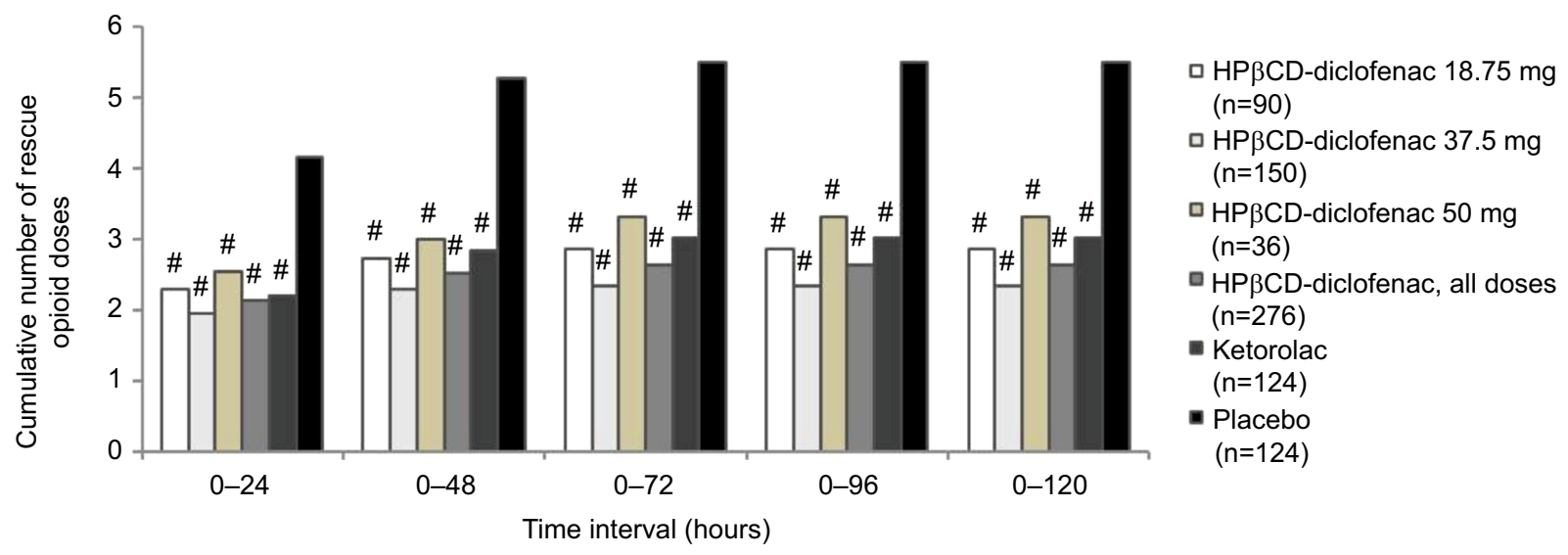

B

Age $\geq 65$ years

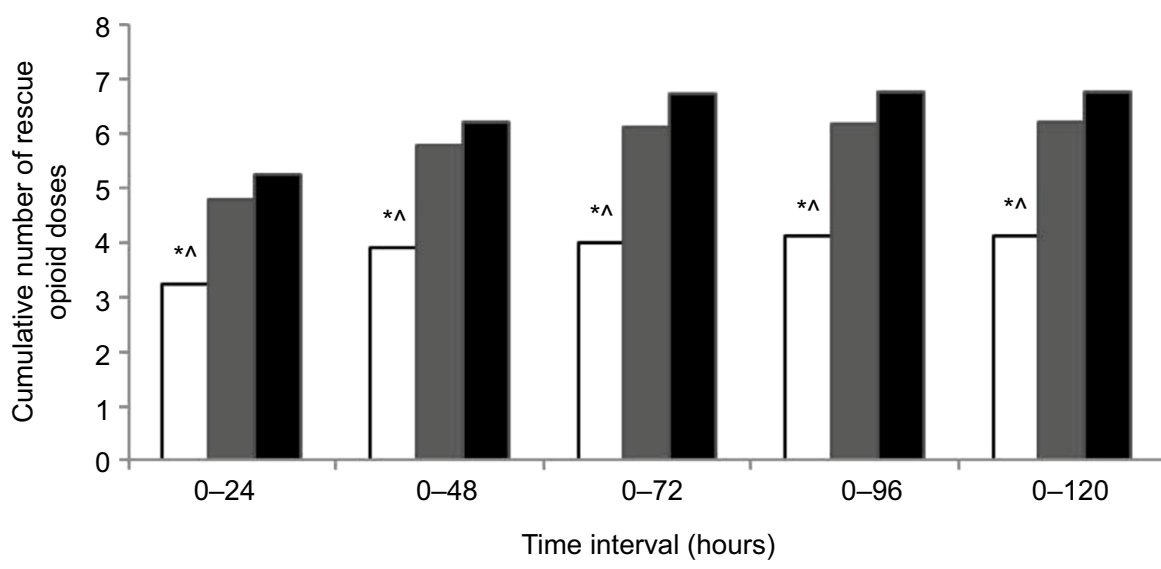

HP $\beta C D$-diclofenac $18.75 \mathrm{mg}$ $(\mathrm{n}=42)$

- Ketorolac

$(n=18)$

- Placebo

$(n=24)$

Figure 6 Total number of rescue opioid doses, by age group, among patients receiving intravenous HP $\beta C D$-diclofenac, ketorolac, or placebo for acute postsurgical pain. Notes: Data are presented for patients aged $(\mathbf{A}) \geq 18$ and $<65$ years and $(\mathbf{B}) \geq 65$ years. Data from the combined ITT populations are presented. $* P<0.05$ versus placebo, ${ }^{\#} P \leq 0.0001$ versus placebo, ${ }^{\wedge} P<0.05$ versus ketorolac from least-square mean difference based on ANCOVA model with treatment, study, and center as factors and baseline pain as a covariate. For mean values and SDs, see Table S4.

Abbreviations: ANCOVA, analysis of covariance; HP $\beta C D$, hydroxypropyl- $\beta$-cyclodextrin; ITT, intent to treat; SD, standard deviation.

monophosphate-potassium channel pathways. ${ }^{33}$ Reasons for the observed differences with respect to opioid sparing between HP $\beta C D$-diclofenac and ketorolac were not examined in the present analysis. However, future studies examining the clinical implications of mechanistic differences between NSAIDs could provide critical insight into the differences between NSAIDs observed in clinical practice.

While the total number of opioid doses was evaluated in patient subgroups based on age ( $<65$ and $\geq 65$ years), it is important to note that cumulative opioid dose was not examined in the context of age in the present analysis. Based on the individual study inclusion criteria, the vast majority of patients $\geq 65$ years old in the pooled population ( $n=82 / 84$, $97.6 \%$ ) were the patients who participated in the orthopedic surgery study, and the effect of HP $\beta C D$-diclofenac on cumulative opioid dose in this patient subgroup has been previously reported. ${ }^{40}$ In line with the current results, Daniels et $\mathrm{a}^{40}$ reported that total opioid consumption was significantly reduced with HP $\beta C D$-diclofenac versus both placebo and ketorolac in patients aged $\geq 65$ years over $0-24$, $0-48,0-72$, and $0-120$ hours. In addition to its effects when given as part of a repeated-dose regimen, the opioid-sparing effects of single-dose HP $\beta C D$-diclofenac have also been demonstrated. Most notably, time to rescue opioid administration following dental surgery was significantly prolonged by a range of HP $\beta C D$-diclofenac doses $(9.4-75 \mathrm{mg}$ ) versus placebo. ${ }^{38}$

The results of the current analysis are also in agreement with evidence for the general opioid-sparing actions of NSAIDs and acetaminophen. ${ }^{2,12,22,23,49-53}$ Administration of oral or IV diclofenac (Voltarol ${ }^{\text {TM }}$ [Novartis Pharmaceuticals 
UK Ltd]; formulated with propylene glycol and benzyl alcohol) has been previously demonstrated to reduce patient-controlled analgesia oxycodone consumption and postoperative nausea and vomiting incidence following knee surgery. ${ }^{52}$ While opioid-sparing effects of ketorolac in the postoperative setting have been demonstrated ${ }^{12,14,22,53}-$ and indeed were evident in the present analysis as well - the results of this study suggest that HP $\beta C D$-diclofenac may be able to support greater opioid sparing than ketorolac in broader surgical practice, an observation consistent with previous findings that diclofenac can provide superior opioid-sparing effects when compared to other NSAIDs. ${ }^{52}$

\section{Conclusion}

In summary, data from this pooled analysis demonstrate that use of HP $\beta C D$-diclofenac in the postoperative setting was associated with reduced opioid consumption in comparison to placebo, and that the standard HP $\beta C D$-diclofenac dose $(37.5 \mathrm{mg}$ ) was associated with significant postoperative opioid sparing over ketorolac in terms of cumulative dose and number of doses, for the 0-48 through $0-120$ hour postoperative time periods. While pooled analyses can present challenges due to between-study heterogeneity, the studies included in the present analysis were amenable to this approach, given their high degree of similarity with respect to study design, inclusion and exclusion criteria, comparators, drug dosages, dosing schedules, and outcome assessment methods. ${ }^{54-56}$

Though the current study provides an in-depth examination of the opioid-sparing effect of HP $\beta C D$-diclofenac, it does not address the important question of the clinical impact of opioid sparing afforded by this diclofenac formulation (ie, impact on opioid-related AEs). Higher postoperative opioid doses have been associated with increased AE risk, ${ }^{5}$ suggesting potentially significant clinical implications of the findings of this analysis. An in-depth examination of opioid-related AEs in patients receiving HP $\beta C D$-diclofenac versus other analgesics will require a larger population than that encompassed by these two studies. Future studies, such as retrospective analyses of deidentified patient data from large electronic health records, would provide additional insight into this important question. Furthermore, such studies could examine the key factors related to recovery from surgery, such as pain upon movement, time to mobility, and length of hospital stay, as well as the outcomes in highly specific patient risk groups, including, for example, patients $\geq 75$ years old.

\section{Acknowledgments}

Editorial/medical writing support was provided by Scott Paluszkiewicz, PhD and Tejaswi Worlikar, MS, MSE of Boston Strategic Partners, Inc., and was funded by Hospira, Inc., which was acquired by Pfizer Inc. in September 2015.

The studies included in the pooled analysis were sponsored by Javelin Pharmaceuticals, Inc., Cambridge, MA (acquired in 2010 by Hospira, Inc., Lake Forest, IL, USA) and Hospira, Inc., which was acquired by Pfizer in September 2015. The present analysis was funded by Hospira, Inc., a Pfizer company.

\section{Disclosure}

TJG, NS, and SED were paid investigators for the studies included in the analysis. PGL was an employee of Hospira, Inc. at the time the study was initiated. CRDR is an employee of Hospira, Inc., a Pfizer company. DAH was the full-time Chief Operating Officer for the study sponsor during the trials included in the present study, and served as a consultant to Hospira, Inc. following its acquisition of Javelin Pharmaceuticals in 2010. DBC was the full-time Chief Medical Officer for the study sponsor during the trials included in the present study, and served as a consultant to Hospira, Inc. following its acquisition of Javelin Pharmaceuticals in 2010.

\section{References}

1. Oderda GM, Evans RS, Lloyd J, et al. Cost of opioid-related adverse drug events in surgical patients. J Pain Symptom Manage. 2003;25(3):276-283.

2. Marret E, Kurdi O, Zufferey P, Bonnet F. Effects of nonsteroidal antiinflammatory drugs on patient-controlled analgesia morphine side effects: meta-analysis of randomized controlled trials. Anesthesiology. 2005;102(6):1249-1260.

3. Carr DB, Goudas LC. Acute pain. Lancet. 1999;353(9169):2051-2058.

4. Bainbridge D, Cheng DC, Martin JE, Novick R, Group E. NSAIDanalgesia, pain control and morbidity in cardiothoracic surgery. Can J Anaesth. 2006;53(1):46-59.

5. Oderda GM, Said Q, Evans RS, et al. Opioid-related adverse drug events in surgical hospitalizations: impact on costs and length of stay. Ann Pharmacother. 2007;41(3):400-406.

6. Hynninen MS, Cheng DCH, Hossain I, Carroll J, Aumbhagavan SS, Yue R, Karski JM. Non-steroidal antiinflammatory drugs in treatment of postoperative pain after cardiac surgery. Can J Anesth. 2000;47(12):1182-1187.

7. Wininger SJ, Miller H, Minkowitz HS, Royal MA, Ang RY, Breitmeyer JB, Singla NK. A randomized, double-blind, placebo-controlled, multicenter, repeat-dose study of two intravenous acetaminophen dosing regimens for the treatment of pain after abdominal laparoscopic surgery. Clin Ther. 2010;32(14):2348-2369.

8. Macintyre PE, Schug SA, Scott DA, Visser EJ, Walker SM. Acute Pain Management: Scientific Evidence. 3rd ed. Melbourne, Australia: Australian and New Zealand College of Anaesthetists and Faculty of Pain Medicine; 2010.

9. White PF, Kehlet H, Neal JM, Schricker T, Carr DB, Carli F. The role of the anesthesiologist in fast-track surgery: from multimodal analgesia to perioperative medical care. Anesth Analg. 2007;104(6):1380-1396. 
10. Minkowitz HS, Gruschkus SK, Shah M, Raju A. Adverse drug events among patients receiving postsurgical opioids in a large health system: risk factors and outcomes. Am J Health Syst Pharm. 2014;71(18):1556-1565.

11. Kessler ER, Shah M, Gruschkus SK, Raju A. Cost and quality implications of opioid-based postsurgical pain control using administrative claims data from a large health system: opioid-related adverse events and their impact on clinical and economic outcomes. Pharmacotherapy. 2013;33(4):383-391.

12. Cepeda MS, Carr DB, Miranda N, Diaz A, Silva C, Morales O. Comparison of morphine, ketorolac, and their combination for postoperative pain: results from a large, randomized, double-blind trial. Anesthesiology. 2005;103(6):1225-1232.

13. Aubrun F, Marmion F. The elderly patient and postoperative pain treatment. Best Pract Res Clin Anaesthesiol. 2007;21(1):109-127.

14. Alexander R, El-Moalem HE, Gan TJ. Comparison of the morphinesparing effects of diclofenac sodium and ketorolac tromethamine after major orthopedic surgery. J Clin Anesth. 2002;14(3):187-192.

15. Lee A, Cooper MG, Craig JC, Knight JF, Keneally JP. Effects of nonsteroidal anti-inflammatory drugs on postoperative renal function in adults with normal renal function. Cochrane Database Syst Rev. 2007;2:CD002765

16. Jarzyna D, Jungquist CR, Pasero C, et al. American Society for Pain Management Nursing guidelines on monitoring for opioid-induced sedation and respiratory depression. Pain Manag Nurs. 2011;12(3):118-145.

17. The Management of Postoperative Pain Working Group, Veterans Health Administration, Department of Defense. VHA/DoD Clinical Practice Guidelines for the Management of Postoperative Pain; July 2001 (updated May 2002). Available from: http://www.healthquality.va.gov/ guidelines/Pain/pop/pop_fulltext.pdf. Accessed February 2, 2016.

18. The Joint Commission. Sentinel Event Alert: Safe Use of Opioids in Hospitals; 2012. Available from: http://www.jointcommission.org/assets/ 1/18/sea_49_opioids_8_2_12_final.pdf. Accessed February 2, 2016.

19. Allen SC, Ravindran D. Perioperative use of nonsteroidal antiinflammatory drugs: results of a UK regional audit. Clin Drug Invest. 2009;29(11):703-711.

20. Jin F, Chung F. Multimodal analgesia for postoperative pain control. J Clin Anesth. 2001;13(7):524-539.

21. Reuben SS. Update on the role of nonsteroidal anti-inflammatory drugs and coxibs in the management of acute pain. Curr Opin Anaesthesiol. 2007;20(5):440-450.

22. Souter AJ, Fredman B, White PF. Controversies in the perioperative use of nonsterodial antiinflammatory drugs. Anesth Analg. 1994;79(6):1178-1190.

23. Elia N, Lysakowski C, Tramer MR. Does multimodal analgesia with acetaminophen, nonsteroidal antiinflammatory drugs, or selective cyclooxygenase- 2 inhibitors and patient-controlled analgesia morphine offer advantages over morphine alone? Meta-analyses of randomized trials. Anesthesiology. 2005;103(6):1296-1304.

24. Turner GA, Gorringe J. Indomethacin as adjunct analgesia following open cholecystectomy. Anaesth Intensive Care. 1994;22(1):25-29.

25. Southworth S, Peters J, Rock A, Pavliv L. A multicenter, randomized, double-blind, placebo-controlled trial of intravenous ibuprofen 400 and $800 \mathrm{mg}$ every 6 hours in the management of postoperative pain. Clin Ther. 2009;31(9):1922-1935.

26. Rugyte D, Kokki H. Intravenous ketoprofen as an adjunct to patient-controlled analgesia morphine in adolescents with thoracic surgery: a placebo controlled double-blinded study. Eur J Pain. 2007;11(6):694-699.

27. Malan TP Jr, Marsh G, Hakki SI, Grossman E, Traylor L, Hubbard RC. Parecoxib sodium, a parenteral cyclooxygenase 2 selective inhibitor, improves morphine analgesia and is opioid-sparing following total hip arthroplasty. Anesthesiology. 2003;98(4):950-956.

28. Laitinen J, Nuutinen L. Intravenous diclofenac coupled with PCA fentanyl for pain relief after total hip replacement. Anesthesiology. 1992;76(2):194-198

29. Kehlet H. Postoperative opioid sparing to hasten recovery: what are the issues? Anesthesiology. 2005;102(6):1083-1085.
30. Camu F, Beecher T, Recker DP, Verburg KM. Valdecoxib, a COX2 -specific inhibitor, is an efficacious, opioid-sparing analgesic in patients undergoing hip arthroplasty. Am J Ther. 2002;9(1):43-51.

31. American Society of Anesthesiologists Task Force on Acute Pain Management. Practice guidelines for acute pain management in the perioperative setting: an updated report by the American Society of Anesthesiologists Task Force on acute pain management. Anesthesiology. 2012;116(2):248-273.

32. Todd PA, Sorkin EM. Diclofenac sodium: a reappraisal of its pharmacodynamic and pharmacokinetic properties, and therapeutic efficacy. Drugs. 1988;35(3):244-285.

33. Gan TJ. Diclofenac: an update on its mechanism of action and safety profile. Curr Med Res Opin. 2010;26(7):1715-1731.

34. Loftsson T, Hreinsdottir D, Masson M. Evaluation of cyclodextrin solubilization of drugs. Int J Pharm. 2005;302(1-2):18-28.

35. Campbell WI, Watters CH. Venous sequelae following i.v. administration of diclofenac. Br J Anaesth. 1989;62(5):545-547.

36. Novartis Pharmaceuticals UK Ltd. Voltarol ${ }^{\circledR}$ Ampoules: summary of product characteristics; 2011. Available from: http://www.medicines. org.uk/emc/medicine/1339/SPC/Voltarol+Ampoules/. Accessed June 8, 2013.

37. Chelly JE, Singla SK, Melson TI, Lacouture PG, Paadre S, Carr DB. Safety of a novel parenteral formulation of diclofenac after major orthopedic or abdominal/pelvic surgery in a population including anticoagulated, elderly or renally insufficient patients: an open-label, multiday, repeated dose clinical trial. Pain Med. 2013;14(5):749-761.

38. Christensen K, Daniels S, Bandy D, et al. A double-blind placebocontrolled comparison of a novel formulation of intravenous diclofenac and ketorolac for postoperative third molar extraction pain. Anesth Prog 2011;58(2):73-81.

39. Gan TJ, Daniels SE, Singla N, Hamilton DA, Carr DB. A novel injectable formulation of diclofenac compared with intravenous ketorolac or placebo for acute moderate-to-severe pain after abdominal or pelvic surgery: a multicenter, double-blind, randomized, multiple-dose study. Anesth Analg. 2012;115(5):1212-1220.

40. Daniels S, Melson T, Hamilton DA, Lang E, Carr DB. Analgesic efficacy and safety of a novel injectable formulation of diclofenac compared with intravenous ketorolac and placebo after orthopedic surgery: a multicenter, randomized, double-blinded, multiple-dose trial. Clin J Pain. 2013;29(8):655-663.

41. Hospira Inc., a Pfizer company. DYLOJECT- diclofenac sodium injection, solution [package insert]. Illinois: Hospira Inc; 2016. Available from: https://dailymed.nlm.nih.gov/dailymed/drugInfo. cfm?setid=dd089777-5479-457a-bc22-3e49d8ae15b1.

42. U.S. Department of Health and Human Services. Food and Drug Administration. Center for Drug Evaluation and Research (CDER). Guidance for Industry. Analgesic Indications: Developing Drug and Biological Products; 2014. Available from: http://www.fda.gov/downloads/drugs/ guidancecomplianceregulatoryinformation/guidances/ucm384691.pdf. Accessed February 2, 2016.

43. Gan TJ, Singla N, Daniels SE, et al. Clinical and laboratory hematologic findings in patients receiving repeated-dose injectable HP $\beta C D$-diclofenac for acute postoperative pain: pooled analysis of two randomized controlled phase III clinical trials. J Anesth Clin Res. 2015;6(7):1000538.

44. Gan TJ, Singla N, Daniels SE, Lacouture PG, Min LH, Reyes CR, Carr DB. Cardiovascular safety of hydroxypropyl- $\beta$-cyclodextrindiclofenac in the management of acute postsurgical pain: a pooled analysis of 2 randomized, double-blind, placebo- and active comparator-controlled phase III clinical trials. J Clin Anesth. 2016; 31:249-258

45. Romsing J, Moiniche S, Mathiesen O, Dahl JB. Reduction of opioidrelated adverse events using opioid-sparing analgesia with COX-2 inhibitors lacks documentation: a systematic review. Acta Anaesthesiol Scand. 2005;49(2):133-142.

46. Oderda GM, Gan TJ, Johnson BH, Robinson SB. Effect of opioid-related adverse events on outcomes in selected surgical patients. J Pain Palliat Care Pharmacother. 2013;27(1):62-70. 
47. Gan TJ, Robinson SB, Oderda GM, Scranton R, Pepin J, Ramamoorthy $\mathrm{S}$. Impact of postsurgical opioid use and ileus on economic outcomes in gastrointestinal surgeries. Curr Med Res Opin. 2015;31(4):677-686.

48. Buvanendran A, Kroin JS. Multimodal analgesia for controlling acute postoperative pain. Curr Opin Anaesth. 2009;22(5):588-593.

49. Remy C, Marret E, Bonnet F. Effects of acetaminophen on morphine side-effects and consumption after major surgery: meta-analysis of randomized controlled trials. Br J Anaesth. 2005;94(4):505-513.

50. Pettersson PH, Jakobsson J, Owall A. Intravenous acetaminophen reduced the use of opioids compared with oral administration after coronary artery bypass grafting. J Cardiothorac Vasc Anesth. 2005;19(3):306-309.

51. Walton GM, Rood JP, Snowdon AT, Rickwood D. Ketorolac and diclofenac for postoperative pain relief following oral surgery. $\mathrm{Br} J$ Oral Maxillofac Surg. 1993;31(3):158-160.
52. Silvanto M, Lappi M, Rosenberg PH. Comparison of the opioid-sparing efficacy of diclofenac and ketoprofen for 3 days after knee surgery. Acta Anaesthesiol Scand. 2002;46(3):322-328.

53. O'Hara DA, Fanciullo G, Hubbard L, Maneatis T, Seuffert P, Bynum $\mathrm{L}$, Shefrin A. Evaluation of the safety and efficacy of ketorolac versus morphine by patient-controlled analgesia for postoperative pain. Pharmacotherapy. 1997;17(5):891-899.

54. Bravata DM, Olkin I. Simple pooling versus combining in meta-analysis. Eval Health Prof. 2001;24(2):218-230.

55. Blettner M, Sauerbrei W, Schlehofer B, Scheuchenpflug T, Friedenreich C. Traditional reviews, meta-analyses and pooled analyses in epidemiology. Int J Epidemiol. 1999;28(1):1-9.

56. Alemayehu D. Perspectives on pooled data analysis: the case for an integrated approach. J Data Sci. 2011;9:389-397. 


\section{Supplementary materials}

Table SI Total rescue opioid consumption and total number of rescue opioid doses among patients receiving intravenous HP $\beta C D$ diclofenac, ketorolac, or placebo for acute postsurgical pain

\begin{tabular}{|c|c|c|c|c|c|c|}
\hline & \multicolumn{6}{|c|}{ Cumulative rescue opioid consumption, mg (SD) } \\
\hline & $\begin{array}{l}\text { HPßCD-diclofenac } \\
\text { 18.75 mg }(n=132)\end{array}$ & $\begin{array}{l}\text { HPßCD-diclofenac } \\
37.5 \mathrm{mg}(\mathrm{n}=150)\end{array}$ & $\begin{array}{l}\text { HPßCD-diclofenac } \\
50 \mathrm{mg}(\mathrm{n}=36)\end{array}$ & $\begin{array}{l}\text { HPßCD-diclofenac } \\
\text { all doses }(n=3 \mid 8)\end{array}$ & $\begin{array}{l}\text { Ketorolac } \\
(n=142)\end{array}$ & $\begin{array}{l}\text { Placebo } \\
(n=148)\end{array}$ \\
\hline \multicolumn{7}{|c|}{ Time interval (hours) } \\
\hline $0-24$ & $7.36(7.47)^{*}$ & $6.11(7.04)^{*}$ & $6.64(6.91)^{*}$ & $6.69(7.21)^{*}$ & $7.4 \mathrm{I}(8.03)^{*}$ & $13.13(9.55)$ \\
\hline $0-48$ & $8.89(9.79)^{*}$ & $7.25(9.22)^{* \wedge}$ & $8.04(8.65)^{*}$ & $8.02(9.40)^{*}$ & $9.74(11.80)^{*}$ & $16.82(13.42)$ \\
\hline $0-72$ & $9.22(10.20)^{*}$ & $7.4 I(9.48)^{*, \wedge}$ & $8.94(10.00)^{*}$ & $8.34(9.85)^{*, \wedge}$ & $10.57(14.64)^{*}$ & $17.67(14.94)$ \\
\hline $0-96$ & $9.31(10.35)^{*}$ & $7.41(9.48)^{* \wedge}$ & $8.94(10.00)^{*}$ & $8.37(9.92)^{*, \wedge}$ & $10.59(14.66)^{*}$ & $17.69(14.94)$ \\
\hline \multirow[t]{3}{*}{$0-120$} & $9.31(10.35)^{*}$ & $7.41(9.48)^{* \wedge}$ & $8.94(10.00)^{*}$ & $8.37(9.92)^{* \wedge}$ & $10.61(14.68)^{*}$ & $17.69(14.94)$ \\
\hline & \multicolumn{6}{|c|}{ Cumulative number of rescue opioid doses (SD) } \\
\hline & $\begin{array}{l}\text { HPßCD-diclofenac } \\
\text { | } 8.75 \mathrm{mg}(\mathrm{n}=132)\end{array}$ & $\begin{array}{l}\text { HPßCD-diclofenac } \\
37.5 \mathrm{mg}(n=150)\end{array}$ & $\begin{array}{l}\text { HPßCD-diclofenac } \\
50 \mathrm{mg}(\mathrm{n}=36)\end{array}$ & $\begin{array}{l}\text { HPßCD-diclofenac } \\
\text { all doses }(n=3 \mid 8)\end{array}$ & $\begin{array}{l}\text { Ketorolac } \\
(n=\mid 42)\end{array}$ & $\begin{array}{l}\text { Placebo } \\
(n=\mid 48)\end{array}$ \\
\hline \multicolumn{7}{|c|}{ Time interval (hours) } \\
\hline $0-24$ & $2.59(2.42)^{*}$ & $1.95(2.38)^{*}$ & $2.56(2.73)^{*}$ & $2.28(2.45)^{*}$ & $2.53(2.78)^{*}$ & $4.34(3.20)$ \\
\hline $0-48$ & $3.11(3.13)^{*}$ & $2.29(2.98)^{* \wedge}$ & $3.00(3.14)^{*}$ & $2.71(3.08)^{*}$ & $3.22(3.55)^{*}$ & $5.42(4.28)$ \\
\hline $0-72$ & $3.22(3.27)^{*}$ & $2.34(3.04)^{* \wedge}$ & $3.33(3.61)^{*}$ & $2.82(3.23)^{* \wedge}$ & $3.42(3.95)^{*}$ & $5.70(4.8 I)$ \\
\hline $0-96$ & $3.26(3.34)^{*}$ & $2.34(3.04)^{* \wedge}$ & $3.33(3.6 \mathrm{I})^{*}$ & $2.83(3.26)^{* \wedge}$ & $3.42(3.97)^{*}$ & $5.70(4.82)$ \\
\hline $0-120$ & $3.26(3.34)^{*}$ & $2.34(3.04)^{* \wedge}$ & $3.33(3.6 \mathrm{I})^{*}$ & $2.83(3.26)^{*, \wedge}$ & $3.43(3.98)^{*}$ & $5.70(4.82)$ \\
\hline
\end{tabular}

Notes: $* P<0.0001$ versus placebo, ${ }^{\wedge} P<0.05$ versus ketorolac from least-square mean difference based on ANCOVA model with treatment, study, and center as factors and baseline pain as a covariate.

Abbreviations: ANCOVA, analysis of covariance; HPBCD, hydroxypropyl- $\beta$-cyclodextrin; SD, standard deviation.

Table S2 Total rescue opioid consumption, by baseline pain severity, among patients receiving intravenous HP $\beta C D$-diclofenac, ketorolac, or placebo for acute postsurgical pain

\begin{tabular}{|c|c|c|c|c|c|c|}
\hline & \multicolumn{6}{|c|}{ Cumulative rescue opioid consumption (SD) } \\
\hline & \multicolumn{6}{|c|}{ Moderate baseline pain ( $\geq 50$ and $<70 \mathrm{~mm}$ on $0-100 \mathrm{~mm}$ VAS) } \\
\hline & $\begin{array}{l}\text { HPßCD-diclofenac } \\
18.75 \mathrm{mg}(\mathrm{n}=84)\end{array}$ & $\begin{array}{l}\text { HPßCD-diclofenac } \\
37.5 \mathrm{mg}(\mathrm{n}=76)\end{array}$ & $\begin{array}{l}\text { HPßCD-diclofenac } \\
50 \mathrm{mg}(\mathrm{n}=23)\end{array}$ & $\begin{array}{l}\text { HPßCD-diclofenac } \\
\text { all doses }(n=183)\end{array}$ & $\begin{array}{l}\text { Ketorolac } \\
(n=82)\end{array}$ & $\begin{array}{l}\text { Placebo } \\
(n=91)\end{array}$ \\
\hline \multicolumn{7}{|c|}{ Time interval (hours) } \\
\hline $0-24$ & $6.81(7.83)^{\#}$ & $4.83(6.38)^{\#}$ & $6.04(6.49)^{\#}$ & $5.89(7.12)^{\#}$ & $6.30(7.48)^{\#}$ & $|2.3|(9.26)$ \\
\hline $0-48$ & $7.99(9.05)^{\#}$ & $5.67(8.00)^{\#, \wedge}$ & $7.72(8.92)^{*}$ & $6.99(8.64)^{\#}$ & $8.70(1 \mathrm{I} .85)^{\#}$ & $15.20(12.34)$ \\
\hline $0-72$ & $8.36(9.58)^{\#}$ & $5.77(8.15)^{\#, \wedge}$ & $8.96(10.73)^{*}$ & $7.36(9.22)^{\#, \wedge}$ & $9.72(15.73)^{*}$ & $15.85(13.60)$ \\
\hline $0-96$ & $8.49(9.85)^{\#}$ & $5.77(8.15)^{\#, \wedge}$ & $8.96(10.73)^{*}$ & $7.42(9.35)^{\#, n}$ & $9.75(15.76)^{*}$ & $15.87(13.59)$ \\
\hline \multirow[t]{3}{*}{$0-120$} & $8.49(9.85)^{\#}$ & $5.77(8.15)^{\#, \wedge}$ & $8.96(10.73)^{*}$ & $7.42(9.35)^{\#, \wedge}$ & $9.78(15.80)^{*}$ & $15.87(13.59)$ \\
\hline & \multicolumn{6}{|c|}{ Severe baseline pain ( $\geq 70 \mathrm{~mm}$ on $0-100 \mathrm{~mm}$ VAS) } \\
\hline & $\begin{array}{l}\text { HPßCD-diclofenac } \\
\text { I8.75 mg }(\mathrm{n}=47)\end{array}$ & $\begin{array}{l}\text { HPßCD-diclofenac } \\
37.5 \mathrm{mg}(\mathrm{n}=73)\end{array}$ & $\begin{array}{l}\text { HPßCD-diclofenac } \\
50 \mathrm{mg}(\mathrm{n}=13)\end{array}$ & $\begin{array}{l}\text { HPßCD-diclofenac } \\
\text { all doses }(n=133)\end{array}$ & $\begin{array}{l}\text { Ketorolac } \\
(n=58)\end{array}$ & $\begin{array}{l}\text { Placebo } \\
(n=57)\end{array}$ \\
\hline \multicolumn{7}{|c|}{ Time interval (hours) } \\
\hline $0-24$ & $8.23(6.83)^{*}$ & $7.44(7.53)^{\#}$ & $7.69(7.75)^{*}$ & $7.74(7.26)^{\#}$ & $9.27(8.55)^{*}$ & $14.44(9.94)$ \\
\hline $0-48$ & $10.35(10.96)^{*}$ & $8.89(10.20)^{\#}$ & $8.62(8.47)^{*}$ & $9.38(10.28)^{\#}$ & $11.59(11.68)^{*}$ & $19.40(14.72)$ \\
\hline $0-72$ & $10.62(11.23)^{*}$ & $9.13(10.54)^{\#}$ & $8.92(8.98)^{*}$ & $9.64(10.60)^{\#}$ & $12.18(13.06)^{*}$ & $20.58(16.58)$ \\
\hline $0-96$ & $10.62(11.23)^{*}$ & $9.13(10.54)^{\#}$ & $8.92(8.98)^{*}$ & $9.64(10.60)^{\#}$ & $12.18(13.06)^{*}$ & $20.58(16.58)$ \\
\hline $0-120$ & $10.62(11.23)^{*}$ & $9.13(10.54)^{\#}$ & $8.92(8.98)^{*}$ & $9.64(10.60)^{\#}$ & $12.18(13.06)^{*}$ & $20.58(16.58)$ \\
\hline
\end{tabular}

Notes: $* P<0.005$ versus placebo, ${ }^{\#} P<0.0001$ versus placebo, ${ }^{\wedge} P<0.05$ versus ketorolac from least-square mean difference based on ANCOVA model with treatment, study, and center as factors and baseline pain as a covariate.

Abbreviations: ANCOVA, analysis of covariance; HPBCD, hydroxypropyl- $\beta$-cyclodextrin; SD, standard deviation; VAS, visual analog scale. 
Table S3 Total number of rescue opioid doses, by baseline pain severity, among patients receiving intravenous HP $\beta C D$-diclofenac, ketorolac, or placebo for acute postsurgical pain

\begin{tabular}{|c|c|c|c|c|c|c|}
\hline & \multicolumn{6}{|c|}{ Cumulative number of rescue opioid doses (SD) } \\
\hline & \multicolumn{6}{|c|}{ Moderate baseline pain ( $\geq 50$ and $<70 \mathrm{~mm}$ on $0-100 \mathrm{~mm}$ VAS) } \\
\hline & $\begin{array}{l}\text { HPßCD-diclofenac } \\
\text { I } 8.75 \mathrm{mg}(\mathrm{n}=84)\end{array}$ & $\begin{array}{l}\text { HPßCD-diclofenac } \\
37.5 \mathrm{mg}(\mathrm{n}=76)\end{array}$ & $\begin{array}{l}\text { HPßCD-diclofenac } \\
50 \mathrm{mg}(\mathrm{n}=23)\end{array}$ & $\begin{array}{l}\text { HPßCD-diclofenac } \\
\text { all doses }(n=183)\end{array}$ & $\begin{array}{l}\text { Ketorolac } \\
(n=82)\end{array}$ & $\begin{array}{l}\text { Placebo } \\
(n=91)\end{array}$ \\
\hline \multicolumn{7}{|c|}{ Time interval (hours) } \\
\hline $0-24$ & $2.37(2.45)^{\#}$ & $1.67(2.47)^{\#}$ & $2.26(2.24)^{\#}$ & $2.07(2.44)^{\#}$ & $2.17(2.42)^{\#}$ & $4.25(3.22)$ \\
\hline $0-48$ & $2.79(2.92)^{\#}$ & $1.99(3.15)^{\#}$ & $2.83(3.00)^{\#}$ & $2.46(3.04)^{\#}$ & $2.93(3.49)^{*}$ & $5.15(4.34)$ \\
\hline $0-72$ & $2.89(3.06)^{\#}$ & $2.01(3.18)^{\#}$ & $3.30(3.72)^{*}$ & $2.58(3.22)^{\#}$ & $3.15(3.97)^{*}$ & $5.40(4.96)$ \\
\hline $0-96$ & $2.95(3.19)^{\#}$ & $2.01(3.18)^{\#}$ & $3.30(3.72)^{*}$ & $2.61(3.28)^{\#}$ & $3.16(4.00)^{*}$ & $5.41(4.96)$ \\
\hline \multirow[t]{3}{*}{$0-120$} & $2.95(3.19)^{\#}$ & $2.01(3.18)^{\#}$ & $3.30(3.72)^{*}$ & $2.61(3.28)^{\#}$ & $3.17(4.02)^{*}$ & $5.41(4.96)$ \\
\hline & \multicolumn{6}{|c|}{ Severe baseline pain ( $\geq 70 \mathrm{~mm}$ on $0-100 \mathrm{~mm}$ VAS) } \\
\hline & $\begin{array}{l}\text { HPßCD-diclofenac } \\
\text { 18.75 mg }(n=47)\end{array}$ & $\begin{array}{l}\text { HPßCD-diclofenac } \\
37.5 \mathrm{mg}(\mathrm{n}=73)\end{array}$ & $\begin{array}{l}\text { HPßCD-diclofenac } \\
50 \mathrm{mg}(\mathrm{n}=13)\end{array}$ & $\begin{array}{l}\text { HPßCD-diclofenac } \\
\text { all doses }(n=133)\end{array}$ & $\begin{array}{l}\text { Ketorolac } \\
(n=58)\end{array}$ & $\begin{array}{l}\text { Placebo } \\
(n=57)\end{array}$ \\
\hline \multicolumn{7}{|c|}{ Time interval (hours) } \\
\hline $0-24$ & $2.91(2.34)^{*}$ & $2.21(2.27)^{\#}$ & $3.08(3.48)^{*}$ & $2.54(2.44)^{\#}$ & $3.12(3.17)^{*}$ & $4.47(3.21)$ \\
\hline $0-48$ & $3.60(3.40)^{*}$ & $2.59(2.79)^{\#}$ & $3.31(3.50)^{*}$ & $3.02(3.10)^{\#}$ & $3.74(3.62)^{*}$ & $5.84(4.20)$ \\
\hline 0-72 & $3.70(3.55)^{*}$ & $2.66(2.89)^{\#}$ & $3.38(3.55)^{*}$ & $3.10(3.21)^{\#}$ & $3.91(3.93)^{*}$ & $6.18(4.58)$ \\
\hline $0-96$ & $3.70(3.55)^{*}$ & $2.66(2.89)^{\#}$ & $3.38(3.55)^{*}$ & $3.10(3.21)^{\#}$ & $3.91(3.93)^{*}$ & $6.18(4.58)$ \\
\hline $0-120$ & $3.70(3.55)^{*}$ & $2.66(2.89)^{\#}$ & $3.38(3.55)^{*}$ & $3.10(3.21)^{\#}$ & $3.91(3.93)^{*}$ & $6.18(4.58)$ \\
\hline
\end{tabular}

Notes: $* P<0.005$ versus placebo, ${ }^{\# P<0.000 I}$ versus placebo versus ketorolac from least-square mean difference based on ANCOVA model with treatment, study, and center as factors and baseline pain as a covariate.

Abbreviations: ANCOVA, analysis of covariance; HP $\beta C D$, hydroxypropyl- $\beta$-cyclodextrin; SD, standard deviation; VAS, visual analog scale.

Table S4 Total number of rescue opioid doses, by age group, among patients receiving intravenous HP $\beta C D$-diclofenac, ketorolac, or placebo for acute postsurgical pain

\begin{tabular}{|c|c|c|c|c|c|c|}
\hline & \multicolumn{6}{|c|}{ Cumulative number of rescue opioid doses (SD) } \\
\hline & \multicolumn{6}{|l|}{ Age $<65$ years } \\
\hline & $\begin{array}{l}\text { HPßCD-diclofenac } \\
\text { 18.75 mg }(n=90)\end{array}$ & $\begin{array}{l}\text { HPßCD-diclofenac } \\
37.5 \mathrm{mg}(n=150)\end{array}$ & $\begin{array}{l}\text { HPßCD-diclofenac } \\
50 \mathrm{mg}(\mathrm{n}=36)\end{array}$ & $\begin{array}{l}\text { HPßCD-diclofenac } \\
\text { all doses }(n=276)\end{array}$ & $\begin{array}{l}\text { Ketorolac } \\
(n=\mid 24)\end{array}$ & $\begin{array}{l}\text { Placebo } \\
(n=124)\end{array}$ \\
\hline \multicolumn{7}{|c|}{ Time interval (hours) } \\
\hline $0-24$ & $2.29(2.17)^{\#}$ & $1.95(2.38)^{\#}$ & $2.56(2.73)^{\#}$ & $2.14(2.37)^{\#}$ & $2.20(2.55)^{\#}$ & $4.16(3.28)$ \\
\hline $0-48$ & $2.74(2.94)^{\#}$ & $2.29(2.98)^{\#}$ & $3.00(3.14)^{\#}$ & $2.53(2.99)^{\#}$ & $2.85(3.35)^{\#}$ & $5.27(4.39)$ \\
\hline $0-72$ & $2.86(3.08)^{\#}$ & $2.34(3.04)^{\#}$ & $3.33(3.6 \mathrm{I})^{\#}$ & $2.64(3.14)^{\#}$ & $3.02(3.75)^{\#}$ & $5.50(4.88)$ \\
\hline $0-96$ & $2.86(3.08)^{\#}$ & $2.34(3.04)^{\#}$ & $3.33(3.6 \mathrm{I})^{\#}$ & $2.64(3.14)^{\#}$ & $3.02(3.75)^{\#}$ & $5.50(4.88)$ \\
\hline \multirow[t]{3}{*}{$0-120$} & $2.86(3.08)^{\#}$ & $2.34(3.04)^{\#}$ & $3.33(3.6 \mathrm{I})^{\#}$ & $2.64(3.14)^{\#}$ & $3.02(3.75)^{\#}$ & $5.50(4.88)$ \\
\hline & \multicolumn{3}{|l|}{ Age $\geq 65$ years } & & & \\
\hline & $\begin{array}{l}\text { HPßCD-diclofenac } \\
\text { 18.75 mg }(n=42)\end{array}$ & Ketorolac $(n=18)$ & Placebo $(n=24)$ & & & \\
\hline \multicolumn{7}{|c|}{ Time interval (hours) } \\
\hline $0-24$ & $3.24(2.8 \mathrm{I})^{*, \wedge}$ & $4.78(3.32)$ & $5.25(2.67)$ & & & \\
\hline $0-48$ & $3.90(3.39)^{* \wedge}$ & $5.78(3.92)$ & $6.21(3.65)$ & & & \\
\hline $0-72$ & $4.00(3.55)^{* \wedge}$ & $6.11(4.36)$ & $6.71(4.43)$ & & & \\
\hline $0-96$ & $4.12(3.73)^{* \wedge}$ & $6.17(4.42)$ & $6.75(4.43)$ & & & \\
\hline $0-120$ & $4.12(3.73)^{* \wedge}$ & $6.22(4.49)$ & $6.75(4.43)$ & & & \\
\hline
\end{tabular}

Notes: $* P<0.05$ versus placebo, ${ }^{*} P \leq 0.0001$ versus placebo, ${ }^{\wedge} P<0.05$ versus ketorolac from least-square mean difference based on ANCOVA model with treatment, study, and center as factors and baseline pain as a covariate.

Abbreviations: ANCOVA, analysis of covariance; $\mathrm{HP} \beta C D$, hydroxypropyl- $\beta$-cyclodextrin; SD, standard deviation; VAS, visual analog scale. 
The Journal of Pain Research is an international, peer reviewed, open access, online journal that welcomes laboratory and clinical findings in the fields of pain research and the prevention and management of pain. Original research, reviews, symposium reports, hypothesis formation and commentaries are all considered for publication
The manuscript management system is completely online and includes a very quick and fair peer-review system, which is all easy to use. Visit http://www.dovepress.com/testimonials.php to read real quotes from published authors. 